\title{
Erratum to: Cell Culture Protection and in vivo Neuroprotective Capacity of Flavonoids
}

\author{
Federico Dajas · Felicia Rivera • Fernanda Blasina • \\ Florencia Arredondo • Carolina Echeverry • \\ Laura Lafon · Andrea Morquio · Horacio Heinzen
}

Published online: 19 September 2013

(C) Springer Science+Business Media New York 2013

Erratum to: Neurotox Res (2003) 5: 425-432

DOI 10.1007/BF03033172

The original publication of this article contained a misspelling in an author name. The name of Horacio Heinzen is reproduced correctly in the author list above.

The online version of the original article can be found under doi:10.1007/BF03033172.

F. Dajas $(\bowtie) \cdot$ F. Rivera · F. Blasina - F. Arredondo ·

C. Echeverry $\cdot$ L. Lafon - A. Morquio $\cdot$ H. Heinzen

Department of Neurochemistry, Instituto de Investigaciones

Biológicas Clemente Estable, Avda Italia 3318, Montevideo,

Uruguay

e-mail: fdajas@iibce.edu.uy

F. Dajas - F. Rivera - F. Blasina - F. Arredondo .

C. Echeverry $\cdot$ L. Lafon - A. Morquio · H. Heinzen

Department of Pharmacognosy, Faculty of Chemistry,

Republic University, 11600 Montevideo, Uruguay 